\title{
New freshwater plesiosaurian materials from the Middle Jurassic Xintiangou Formation of the Sichuan Basin, southwestern China
}

\author{
Feng Zhang ${ }^{1}$, Hai-Dong Yu' ${ }^{1}$, Can Xiong ${ }^{1}$, Zhao-Ying Wei ${ }^{1}$, Guang-Zhao Peng ${ }^{2}$ and Xue-Fang Wei ${ }^{3,4,5^{*}}$ (D)
}

\begin{abstract}
Sichuan Basin is very famous for the Mesozoic reptiles, especially the Jurassic dinosaurs. Here, we report some isolated plesiosaurian teeth and vertebrae newly excavated from the Middle Jurassic Xintiangou Formation in Yunyang county, Chongqing City, the northeastern region of the Sichuan Basin, southwestern China. The specimens are referred to Pliosauroidea based on the combination of the following features: the circular cross-section of the tooth crown, apicobasal ridges fully covering the enamel surface and reaching to the apex, the short and amphicoelous centrum, the centrum shorter than wide or tall, and the absence of a keel on the lateral surface of the cervical centrum. With the fragmentary nature, it is undetermined whether the Yunyang specimens belong to a known taxon or represent a new species of Plesiosauria. These plesiosaurian specimens further demonstrate that the freshwater plesiosaurians are common in the Jurassic deposits of the Sichuan Basin. For a comprehensive knowledge of the plesiosaurians of the basin in origin, distribution and diversity, to discover new and more complete specimens is necessarily the first priority.
\end{abstract}

Keywords: Plesiosauria, Pliosauroidea, Middle Jurassic, Xintiangou formation, Sichuan Basin

\section{Introduction}

Plesiosaurians are Mesozoic aquatic reptiles generally with a "fish-shaped" body plan. They show a short stiff trunk, a relatively short tail, four limbs modified into flippers, and a highly variable neck length and skull size. Based on the neck length and skull size, plesiosaurians are generally grouped into two major assemblages, i.e. Pliosauroidea (for those short necked and large headed) and Plesiosauroidea (for those small headed and long necked) as well as some intermediate morphotypes (Brown 1981; O’Keefe 2002; Ketchum and Benson 2010; Benson et al. 2013a, 2013b; Benson and Druckenmiller 2014). Plesiosaurians are distributed globally, mainly in the Jurassic and

\footnotetext{
*Correspondence: weixuefang1208@163.com

${ }^{3}$ Institute of Geology, Chinese Academy of Geological Sciences, Beijing 100037, China

${ }^{4}$ China University of Geosciences (Beijing), Beijing 100083, China

Full list of author information is available at the end of the article
}

Cretaceous marine deposits (Welles 1943; Tarlo 1960; Brown 1981; Sues 1987; Tschanz 1989; Storrs 1991; Sato 1998; Sato et al. 2006; Benson and Druckenmiller 2014; Cau and Fanti 2014; Sato et al. 2018; Zverkov et al. 2018). Plesiosaurian remains from freshwater environments are comparatively rare, which mainly come from England (Andrews 1922; Kear and Barrett 2011; Benson et al. 2012, 2013a), Germany (Hampe 2013; Hornung et al. 2013; Sachs et al. 2017), Canada (Sato et al. 2005; Sato and Wu 2006; Vandermark et al. 2006; Vavrek et al. 2014), Australia (Bartholomai 1966; Thulborn and Warren 1980; Wiffen et al. 1995; Kear 2006, 2007, 2012; Vajda and Raine 2010; Benson et al. 2013b), New Zealand (Cruickshank and Fordyce 2002), China (Young 1942, 1944, 1973; Dong 1980; Zhang 1985; Wu 1987; Xiao et al. 1991; Gao et al. 2004, 2019; Peng et al. 2005), and South Africa (Cruickshank 1997). 
In China, all reported plesiosaurian remains come from freshwater deposits and are very fragmentary with no skull preserved. They were known from the Lower to Middle Jurassic formations of the Sichuan Basin (Young 1942, 1944; Dong 1980; Zhang 1985; Gao et al. 2004; Peng et al. 2005), the Upper Triassic Shezi Formation of Yunnan Province (Xiao et al. 1991), the Upper Cretaceous Napai Formation of Guangxi Province (Hou et al. 1975), the Middle Jurassic Xinhe Formation of Gansu Province (Gao et al. 2019) and the Lower Cretaceous Wu'erhe Formation of Xinjiang Province (Young 1973; Wu 1987). The Guangxi plesiosaurian specimens of Hou et al. (1975) originally named as Sinopliosaurus fusuiensis were reconsidered as a spinosaurid theropod dinosaur (Buffetaut et al. 2008). The Yunnan plesiosaurian specimens of Xiao et al. (1991) represented by three incomplete teeth were assigned to a new species of Sinopliosaurus sheziensis. The Gansu plesiosaurian material of Gao et al. (2019) was considered as an indeterminate genus and species within the Plesiosauria. The plesiosaurian specimens of Xinjiang were referred to Sinopliosaurus weiyuanensis Young 1944. The plesiosaurian specimens from the Sichuan Basin were all assigned to Pliosauroidea, namely Sinopliosaurus weiyuanensis (Young 1944), Bishanopliosaurus youngi (Dong 1980), Bishanopliosaurus zigongensis (Gao et al. 2004) and Yuzhoupliosaurus chengiiangensis (Zhang 1985).

Here, we report some plesiosaurian specimens from the lower Middle Jurassic Xintiangou Formation in Yunyang county, Chongqing City, the northeastern Sichuan Basin, southwestern China.

\section{Geological background}

Plesiosaurian specimens of Yunyang county were collected in Laojun village, Pu'an town, Yunyang county, Chongqing, the northeastern Sichuan Basin, southwestern China (Fig. 1). The basin is a Mesozoic continental basin and famous for abundant Jurassic dinosaur fossils

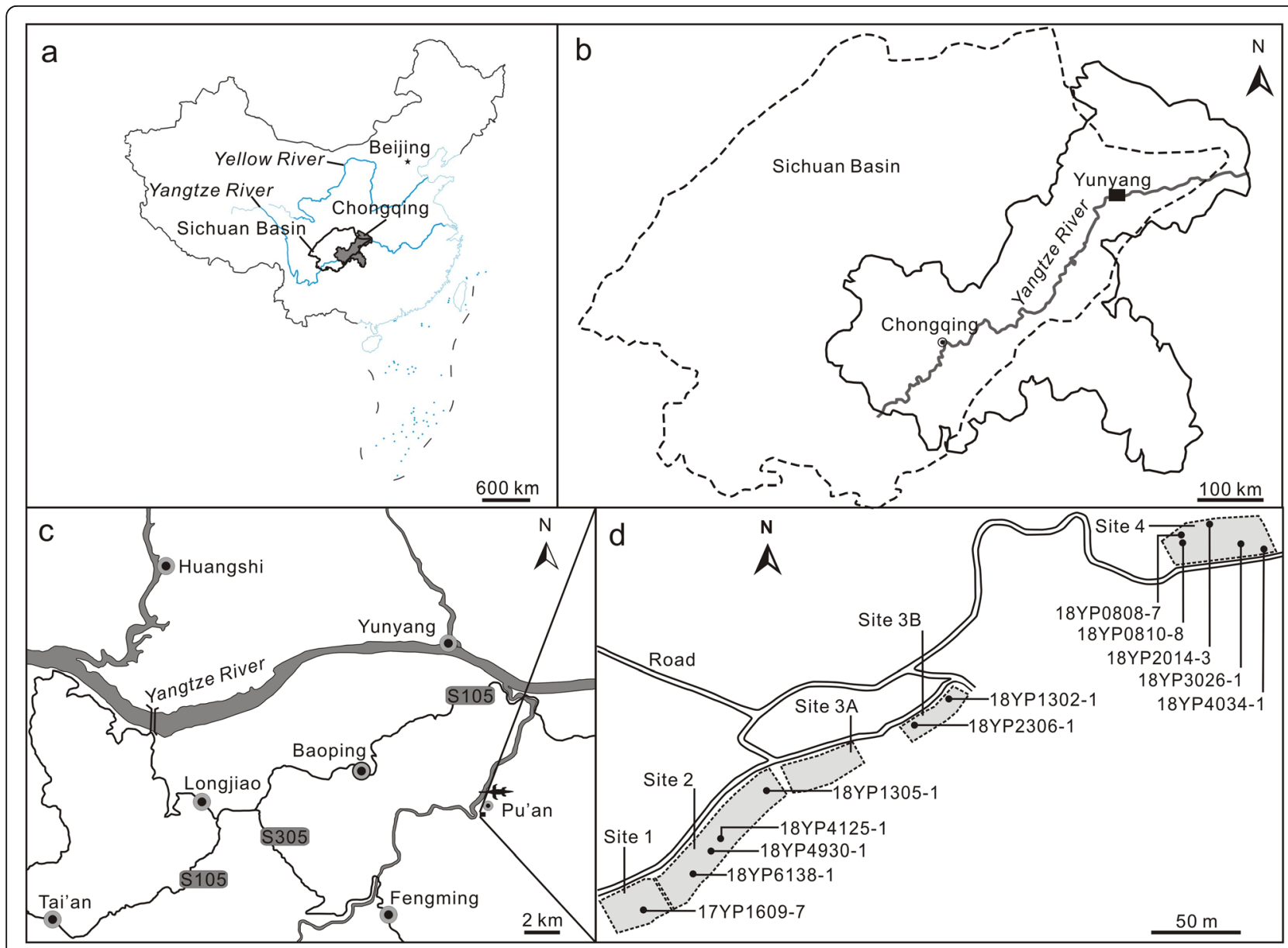

Fig. 1 Maps showing the locality of pliosauroid fossils in Yunyang. a A sketch map of China showing the geographical locations of Sichuan Basin and Chongqing City. The base map of China is modified after the Standard Map Service of the National Administration of Surveying, Mapping and Geoinformation of China (http://bzdt.ch.mnr.gov.cn/) (No. GS (2016)1585); b Locality of Yunyang county (marked by a black rectangle); c Locality of Pu'an town in Yunyang (marked by a black rectangle and pliosauroid silhouette); d Fossil sites in Pu'an town 
and tracks (Young 1941; Peng et al. 2005; Wang 2008; Wang et al. 2008, 2010; Ye et al. 2012; Li 2016). Our fieldwork shows that the fossiliferous strata belong to the Jurassic Xintiangou Formation. The formation is widely distributed in the Sichuan Basin, which conformably contacts the underlying Ziliujing Formation and the overlying Xiashaximiao Formation. In Yunyang area, the Xintiangou Formation is more than $424.7 \mathrm{~m}$ in thickness. It consists of purplish red argillite and yellowish grey siltstones. The presence of abundant bivalves indicates that the formation originated from a typical freshwater lacustrine environment. The $\mathrm{U}-\mathrm{Pb}$ dating suggests that the formation is about $180-170 \mathrm{Ma}$ corresponding to the late Toarcian-Aalenian (Li et al. 2019).

The fossil specimens of this study came from a steep slope (with a strike direction of $335^{\circ}$ and a dip angle of $26^{\circ}-35^{\circ}$ ) of a hill of the upper Xintiangou Formation. The fossiliferous layer varies in thickness from $0.3 \mathrm{~m}$ to $0.7 \mathrm{~m}$ and reaches maximally $1 \mathrm{~m}$ in certain places. The fossil specimens are abundant but isolated and disarticulated, being scattered around or not closely associated. They are concentrated in four sites of the fossilizations layer within a maximal distance of about $450 \mathrm{~m}$ (Fig. 1d). The specimens vary in size and the surface of teeth bears clear abrasions. These specimens show a heterochthonous burial state and possibly experienced a longdistance transportation before accumulated and buried together in Yunyang area. With plesiosaurian specimens, there are also rich dinosaur bones discovered together, such as those of a basal sauropodomorphs (Tan et al. 2019), of an ornithopod ( $\mathrm{Li}$ et al. 2019), as well as much more unstudied.

\section{Materials and methods}

\subsection{Specimens}

All plesiosaurian specimens are housed in Chongqing Laboratory of Geoheritage Protection and Research (CLGPR), No. 208 Hydrogeological and Engineering Geological Team, Chongqing Bureau of Geological and Mineral Resource Exploration and Development, with a catalogue number of CLGPR V00004. Among the preserved specimens, we selected four teeth, seven vertebrae and two ribs from four sites as a base for this study because they are better preserved than others and can represent the morphotypes of plesiosaurians of the upper Xintiangou Formation in Yunyang area. Of the seven vertebrae, three (18YP1305-1, 18YP0808-8 and 18YP2014-3) belong to the cervical section, one (18YP0808-7) comes from the dorsal section and the other three (17YP1609-7, 18YP2306-1 and 18YP4125-1) belong to the caudal section of the vertebral column based on the position of the transverse process for the rib. In plesiosaurians, the transverse process (rib facet) is entirely located on the lateral side of the centrum or never reaches the suture of the centrum with the neural arch in the cervical vertebrae (see Brown 1981: fig. 8; Sato et al. 2003: fig. 1a). Contrarily, the transverse process is entirely placed on the lateral side of the neural arch in dorsal vertebrae (see Brown 1981: figs. 9, 11; Benson et al. 2012: fig. 1). The position of the transverse process overlaps the suture of the centrum and neural arch in the sacral vertebrae and anterior caudal vertebrae (see Brown 1981: fig. 12; Sato et al. 2003: fig. 2), but entirely back to the lateral side of the centrum in posterior caudal vertebrae (see Sachs et al. 2016: fig. 17).

According to Brown (1981), in adults of plesiosaurians, the centra are strongly amphicoelous and central margins are more rounded and rugose. The centra from Yunyang are moderately amphicoelous and not fused with their neural arches, which indicate that they most probably represent juvenile individuals.

\subsection{Methods}

Measurements are taken using a calliper from the true specimens, and photographed using Canon D530 camera. Images are prepared by Adobe Photoshop CS6 and CorelDRAW X4. Fossil's site data were collected by us in the fieldwork.

\section{Systematic Palaeontology}

Sauropterygia Owen 1860

Plesiosauria de Blainville 1835

Pliosauroidea Welles 1943, sensu O'Keefe 2001

Gen. et sp. indet.

\subsection{Locality and horizon}

Laojun village, Pu'an town, Yunyang county, Chongqing, China; lower Middle Jurassic, upper part of the Xintiangou Formation.

\subsection{Description}

4.2.1 Teeth

All teeth collected are represented by the crown portion. The terminology used to describe the morphology and outer enamel structures here follows Zverkov et al. (2018). Tooth crowns are robust. Their enamel surfaces are fully covered by apicobasal ridges or striations. They vary in size (height from $20 \mathrm{~mm}$ to $55 \mathrm{~mm}$ ), and the width-to-length ratio of tooth crowns ranges from 0.28 to 0.4 . As represented by the four teeth (Table 1 ), the teeth are slightly curved linguodistally (Figs. 2, 3). The apex is not sharply pointed because it was worn off. The apicobasal ridges are almost regularly distributed around the entire surface of the crown. Most of the assessable ridges extend through the whole apicobasal height of the crown. The labial ridges are slightly more distantly spaced than their lingual counterparts are. In apical view, most of the ridges reach to the apex. On the crown 


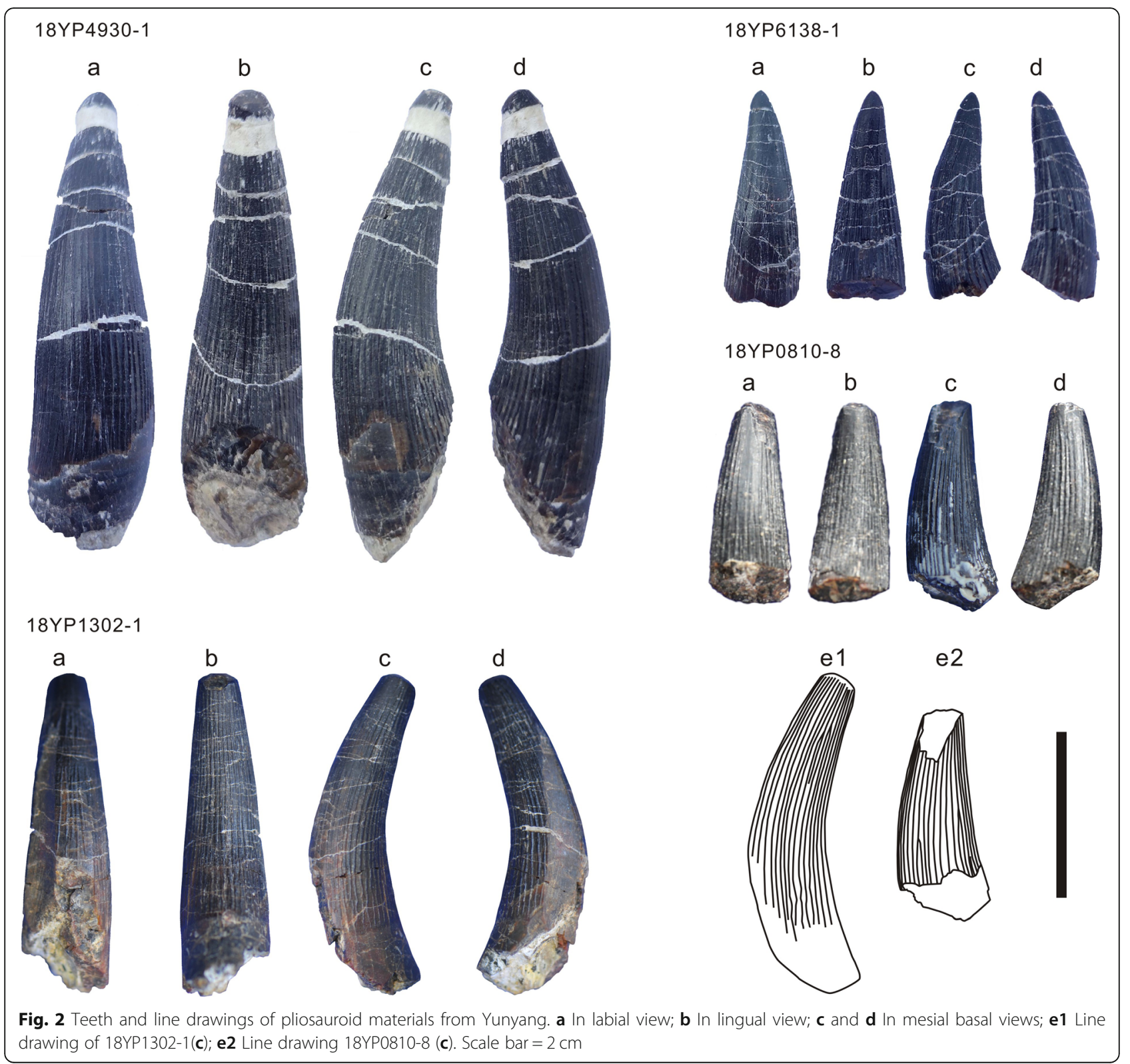

base, the ridges appear vermicular. The crown is conical and nearly circular in cross-section. Abrasion traces are present among the apicobasal ridges, which were possibly caused by a long-distance transportation or predation behaviour. In tooth 18YP1302-1, there is an arcshaped worn facet and the ridge branching is present in two places around the base of the crown (Fig. 2). Abruption of some ridges occurs on the basal part of the crown surface. Teeth are widely distributed in sites 2-4.

According Gao et al. (2019), the tooth crowns of a large body-sized plesiosaurs are not less than $36 \mathrm{~mm}$ in length (height), while in small body-sized individuals, the tooth crowns range from $4.5 \mathrm{~mm}$ to $54 \mathrm{~mm}$. As shown in Table 1, crowns of some teeth of the Yunyang plesiosaurians reach $55 \mathrm{~mm}$ in height, which suggests that there were large-sized plesiosaurians (possibly more than $4 \mathrm{~m}$ long) lived in Yunyang during the early Middle Jurassic.

\subsubsection{Cervical vertebrae}

Of the three cervical vertebrae described here, cervical 18YP1305-1 comes from site 2. Its centrum is preserved while its neural arch is missing. The centrum is moderately amphicoelous (Fig. 3). The anterior articular surface is deep and the posterior one is shallow. The centrum is shorter than wide or high, with a lengthwidth ratio of 1:1.85 and a length-height ratio of 1:1.6 (see Table 1). The transverse process for the rib is moderately developed on each side of the centrum; its crosssection is oval in outline, with diameters of $22 \mathrm{~mm}$ and 
Table 1 Measurements of the selected specimens (each with a field number) from Yunyang in this study (in mm)

\begin{tabular}{|c|c|c|c|c|c|}
\hline Items & Field number & Length & Width & Height & Locality \\
\hline \multirow[t]{4}{*}{ Tooth crowns } & 18YP4930-1 & 55 & 15 (base) & - & Site 2 \\
\hline & 18YP6138-1 & 25 & 10 (base) & - & Site 2 \\
\hline & 18YP1302-1 & 36 & 13 (base) & - & Site $3 B$ \\
\hline & 18YP0810-8 & more than 25 & 12 (base) & - & Site 4 \\
\hline \multirow[t]{3}{*}{ Cervicals } & 18YP1305-1 & 36 & 66 & 57 & Site 2 \\
\hline & 18YP0808-8 & 40 & 70 & 68 & Site 4 \\
\hline & 18YP2014-3 & 25 & 40 & 32 & Site 4 \\
\hline Dorsals & 18YP0808-7 & 29 & 55 & 47 & Site 4 \\
\hline \multirow[t]{3}{*}{ Caudals } & 17YP1609-7 & 38 & 60 & 64 & Site 1 \\
\hline & 18YP2306-1 & 27 & 38 & 40 & Site 3B \\
\hline & 18YP4125-1 & 20 & 32 & 33 & Site 2 \\
\hline \multirow[t]{2}{*}{ Ribs } & 18YP3026-1 & - & 13 (shaft) & - & Site 4 \\
\hline & 18YP4034-1 & - & 11 (shaft) & - & Site 4 \\
\hline
\end{tabular}

$14 \mathrm{~mm}$, respectively. The process is ventrally positioned and extends downwards and backwards. The ventral surface of the centrum bears a weak keel (antero-posteriorly oriented) which only extends to the half-length of the centrum. Two small foramina are present on each side of the ventral surface. In dorsal view, the articular facet for the neural arch on each side is deeply concave. Margins of the centrum are obscured because of erosion during transportation before the vertebra was covered by sediments.

Cervical vertebra $18 Y$ P0808-8 is from site 4 . Its centrum is well preserved, with the upper part anteroposteriorly compressed (Fig. 3). The centrum is gently amphicoelous. It is shorter than wide or high, with a length-width ratio of 1:1.75 and a length-height ratio of 1:1.7 (see Table 1). The transverse process for the rib is partly preserved and the shape of its cross-section is obscured due to damage. The ventral surface bears a weakly developed ridge, which appears thicker compared with that of centrum 18YP1305-1. Three foramina can be seen on the ventral surface, two on the left side. In dorsal view, the articular facet for the neural arch on each side is very concave but deformed during preservation. It is difficult to see whether the facet merges with the transverse process owing to poor preservation. Margins of the centrum are obscured due to erosion during transportation before the vertebra was covered by sediments.

Cervical vertebra 18YP2014-3 is also from site 4. The vertebra preserves centrum only (Fig. 3). It is strongly amphicoelous. The concave anterior articular surface is convex around the margin and deeply hollow at the centre. The concave posterior articular surface is slightly convex around the margin and shallowly depressed inwards. The centrum is sub-circle in cross-section. It is shorter than wide or tall, with a length-width ratio of 1 : 1.6 and a length-height ratio of 1:1.3 (see Table 1). The transverse process is moderately developed; its facet is oval in outline, with a long axis of $12 \mathrm{~mm}$ and a short axis of $10 \mathrm{~mm}$, respectively. The ventral surface is gently convex and bears no foramen. There is no ventral keel developed. In dorsal view, the articular facet for the neural arch on each side is deeply concave and distantly spaced from its counterpart. The rib facet is dorsally very close to the articular facet for the neural arch, indicating that 18YP2014-3 represents a posterior cervical vertebra. Margins around the centrum are obscured owing to erosion during transportation before sediments covered the vertebra.

\subsubsection{Dorsal vertebra}

Dorsal vertebra 18YP0808-7 also comes from site 4. It is the only dorsal vertebra showing some morphological features. Its centrum is well preserved (Fig. 3). The centrum is evidently amphicoelous. As in the aforementioned cervical vertebrae, the centrum is shorter than wide or high. It is very short, about half of its width (ratio of $1: 1.9$ ). The length-height ratio reaches $1: 1.6$ (see Table 1). There is no transverse process for the rib on the lateral surface, indicating that it belongs to the dorsal section of the vertebral column. The ventral surface bears three small foramina but no keel. The smooth lateral and ventral surfaces of the centrum are strongly concave. The anterior and posterior articular surfaces are circular. In dorsal view, the articular facet for the neural arch on each side is evenly concave anteroposteriorly. Margins of the centrum are obscured due to erosion during transportation before sediments covered the vertebra. 


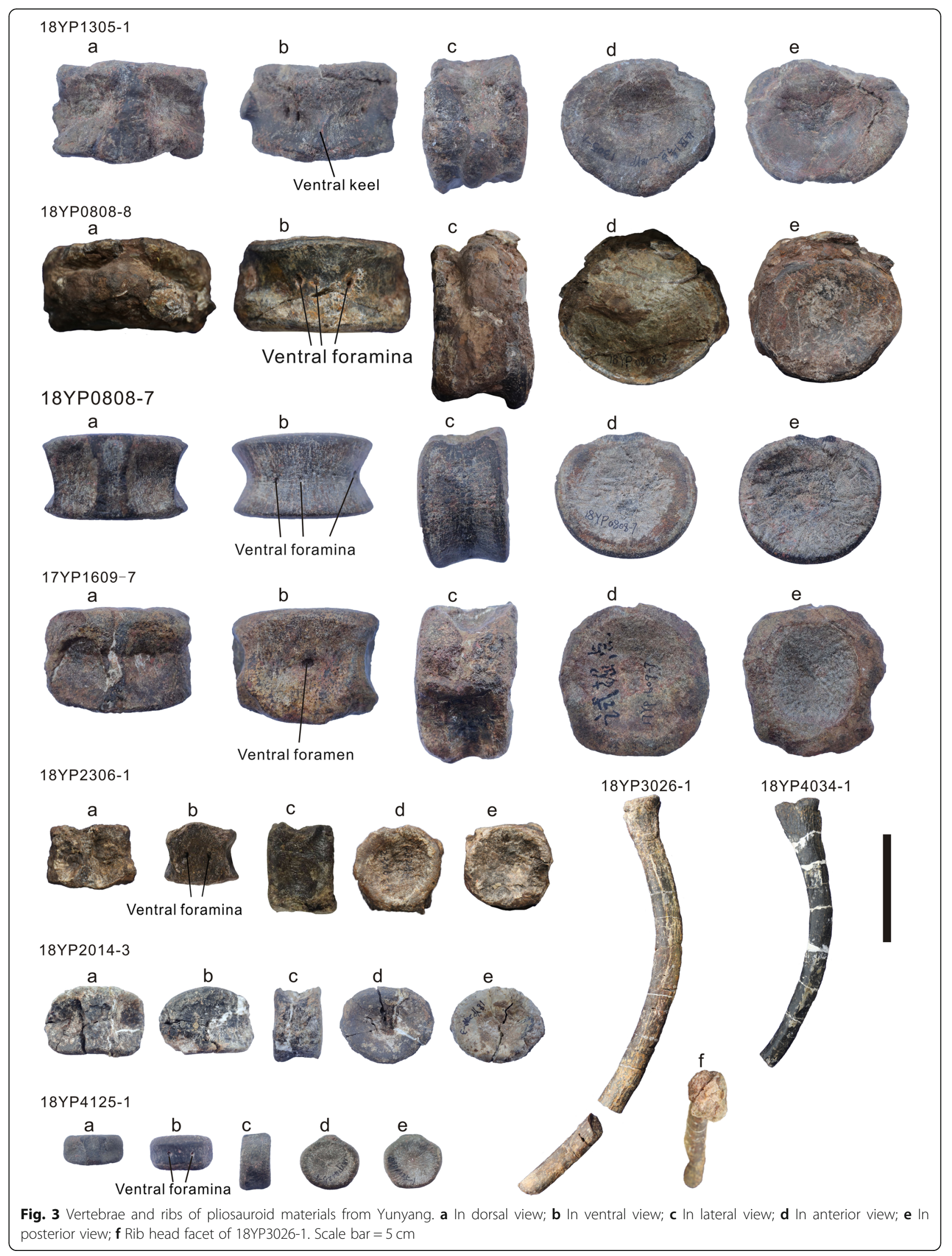




\subsubsection{Caudal vertebrae}

Of the three caudal vertebrae, vertebra 17YP1609-7 was collected from site 1 . Only the centrum is preserved (Fig. 3). The centrum is moderately amphicoelous. The centrum has a length-width ratio of about 1:1.6 and a length-height ratio of about 1:1.7, respectively. The lower part of the lateral surface is concave inwards and the rough upper part represents the rib facet which occupies the upper centrum in addition to the lower neural arch. In dorsal view, the concave articular facet for the neural arch on each side shows a triangular depression. The ventral surface is flat and bears one big foramen at the midline. There are two pairs of facets for the chevron on the anteroventral and posteroventral edges of the centrum. The anterior pair is much bigger than the posterior pair. The transverse process is broad and reaches the articular facet for the neural arch, which means that the transverse process crossed the suture of the centrum to the neural arch. By extension, it indicates that this centrum represents an anterior caudal vertebra. Margins of the centrum are obscured due to erosion during transportation before sediments covered the vertebra.

Vertebra 18YP2306-1 comes from site 3. The centrum is preserved while the neural arch is missing (Fig. 3). The centrum is strongly amphicoelous and short, with a nearly circular cross-section. The length-width ratio is similar to the length-height ratio, separately reaching to 1:1.4 and 1:1.5 (see Table 1). The lateral surface is gently smooth and concave, with the rib facet positioned dorsally and meeting the facet for the neural arch. The latter suggests that vertebra 18YP2306-1 probably represents an anterior caudal vertebra. The dorsal surface for the neural arch is shallowly concave. The ventral surface is very flat and bears a big foramen on each side to the midline. The anterior pair of the chevron facets is much bigger than the posterior pair. Margins around the centrum are relatively rough and obscured due to erosion during transportation before sediments covered the vertebra.

Vertebra 18YP4125-1 was collected from site 2. The centrum is preserved. It is very short and small, with a circular cross-section (Fig. 3). It is weakly amphicoelous. As in 18YP2306-1, the length-width ratio is close to the length-height ratio (about 1:1.6 and 1:1.65, respectively). The lateral surface is smooth and nearly flat. There is a nub-like pronounce on the lateral surface, which may represent a remnant of a transverse process. If so, this centrum is one of the posterior-most section of the caudal vertebrae. The lateral surface is naturally transitional to ventral surface with no concavity inwards. The ventral surface is even weakly convex and bears no chevron facets but a pair of foramina. The dorsal articular facet for the neural arch on each side is deeply concave. Margins around the centrum are relatively rough and rounded in outline, which may have been exaggerated by erosion during transportation before sediments covered the vertebra.

\subsubsection{Ribs}

Ribs 18YP3026-1 and 18YP4034-1 are both from site 4 (Fig. 3). The ribs are incomplete, with distal portion missing. The rib head is moderately enlarged, with a slightly concave facet for the transverse process of the vertebrae. The rib head facet of 18YP3026-1 is longitudinal ovoid, with $23 \mathrm{~mm}$ and $32 \mathrm{~mm}$ in diameter, respectively. The rib shaft is curved and clavate, and the cross-section is almost circular. The inner surface of the ribs twists slightly. In morphology, the ribs are similar to that of B. youngi (Peng et al. 2005) and considered as two dorsal ribs based on its length and single-headed appearance.

\section{Results and discussion}

Tarlo (1960) concluded that the teeth, mandibles, cervical vertebrae, scapulae and epipodials (radii, ulnae, tibiae and fibulae) were much useful in making comparisons among different species; the propodials (humeri and femora) were of very limited value to taxonomic comparisons; and the cervical vertebrae, particularly the presence or absence of a ventral keel, could best affect specific distinctions. Thus, we herein use the morphological characters of the teeth and cervical vertebrae to make comparisons with other taxa.

In Plesiosauroidea, the tooth ornament is reduced, and the apicobasal ridges mostly interrupt and do not extend to the apex, while in Pliosauroidea, the tooth apicobasal ridges are dense and most extend from the base to the apex (Tarlo 1960; Brown 1981). The plesiosaurian teeth from Yunyang are all well decorated with the apicobasal ridges arranged in the pliosauroid pattern, thus they are reasonable to be referred to Pliosauroidea. The teeth of Pliosauroidea are commonly divided into two types (Fischer et al. 2015). In one type, tooth crowns are conical with a circular cross-section but no carinae on enamel surface. Pliosauroids with this type of teeth mainly lived in the Early Jurassic and Middle Jurassic. The other type has been considered to be derived, the crowns with a subtrihedral-trihedral cross-section and one to three carinae on the enamel surface. Pliosauroids with such a type of teeth mainly lived in the Late Jurassic to Early Cretaceous (Tarlo 1960; Ketchum and Benson 2010; Kear and Barrett 2011; Kear 2012; Benson et al. 2013a; Benson and Druckenmiller 2014; Fischer et al. 2015; Sassoon et al. 2015; Madzia 2016; Madzia and Machalski 2017; Zverkov et al. 2018). With our comparisons, the plesiosaurian teeth from Yunyang are morphologically compatible with those of Jurassic pliosaurids, showing a robust and curved tooth crown that is conical in outline, 
usually has a worn off on the tip and apicobasal ridges which are closely spaced, reach to the apex and fully cover the enamel surface. In addition, there are few or no ridge branching and no carinae on the crown surface (Tarlo 1960; Brown 1981; Benson and Druckenmiller 2014).

Compared to the conical tooth crowns of non-marine Pliosauroidea from China, England, Canada, and Australia (Kear 2006, 2012), the pliosauroid tooth crowns from Yunyang are different in ornaments and general morphology. The tooth tip is not as pointed as in $Y$. chengjiangensis (Zhang 1985). The crown is relatively shorter and less curved than in B. youngi (Peng et al. 2005). The ridges are more densely spaced than in the plesiosaur teeth from Gansu (Gao et al. 2019). The ridges are not as often interrupted as in Simolestes nowackianus (Huene 1938) which was further reinterpreted as a teleosaurid crocodile rather than a pliosaur (Bardet and Hua 1996). The ridges extend much more basal on the crown than in Simolestes vorax (Andrews 1909). There are more ridges reaching to the apex than in Liopleurodon ferox (Sauvage 1873). There are relatively more ridges (or more densely spaced) on the enamel surface than in Liopleurodon pachydeirus (Seeley 1869) and Pliosaurus andrewsi (Tarlo 1960). There are no inserted ridges that are seen in Peloneustes philarchus (Seeley 1869) from England (Tarlo 1960; Madzia 2016). When compared with those taxa from the Cretaceous, Yunyang pliosauroid teeth are very different in that there are most ridges reaching to the crown tip, no short ridges occurring in the middle of the crown and no ridges reduction on the labial surface. Those features are opposite in an elasmosaurid (a plesiosauroid) from the Lower Cretaceous, Canada (Sato and Wu 2006; Vandermark et al. 2006). There are more ridges reaching to the apex and covering the labial surface than in the pliosaurid teeth from the Lower Cretaceous, Australia (Benson et al. 2013b). Similarly, the differences between the Yunyang pliosauroid teeth and the aforementioned Cretaceous taxa are also true when compared with pliosaurid teeth from the Lower Cretaceous of Germany (Hampe 2013), South Africa (Cruickshank 1997) and southern England (Kear and Barrett 2011). Following the above comparisons, the pliosauroid teeth from Yunyang cannot be referred to any known pliosauroids from the Sichuan Basin (such as $Y$. chengjiangensis and B. youngi) or an unnamed plesiosauroid from Gansu, which only have teeth preserved. The Yunyang pliosauroid teeth also differ from those of the Upper Triassic Shezi Formation in that the crown ridges are much more densely spaced in the former than in the latter. Sinopliosaurus weiyuanensis from the Sichuan Basin only has one incomplete tooth preserved. This tooth bears very fine ridges (striations), an oval cross-section and a labial-lingually unsymmetrical crown (Young 1944: Fig. 3b in Plate II). These tooth features indicate that the pliosauroid teeth from Yunyang cannot be referred to $S$. weiyuanensis either. Since other Chinese pliosauroids do not have teeth preserved, we can only make a comparison of the preserved vertebrae between those forms and the Yunyang pliosauroid.

All the plesiosaurian vertebral centra found in Yunyang show a set of characters more similar to pliosauroids than to plesiosauroids. In nearly all shortnecked pliosauroid forms, the anterior cervical vertebrae do not have a lateral keel, which is almost invariably present in long-necked plesiosauroid forms, although there is a high degree of variability in ontogeny, intraspecific and taxonomic variations (Brown 1981; Benson and Druckenmiller 2014). It also should be noticed that the ventral keel might disappear towards the back of the neck in all plesiosaurians (Brown 1981; O'keefe and Hiller 2006; Benson and Druckenmiller 2014). We herein take the absence of the lateral keel of the cervical centrum for a diagnostic character and further consider that the vertebrae from Yunyang most probably come from a pliosauroid. The plesiosaurian dorsal and caudal centra from Yunyang also possibly belong to a pliosauroid if the cervical vertebrae from the same sites are considered to represent a pliosauroid. These vertebral centra are clearly shorter than wide or tall as in many pliosauroids. In most plesiosauroids, the centrum can be as long as wide (Brown 1981; O'Keefe and Hiller 2006).

Compared with those Chinese pliosauroids with vertebrae preserved, the cervical centra with a ventral keel and foramina are most similar to that of B. youngi (Dong 1980; Sato et al. 2003). The dorsal centrum without a ventral keel is similar to that of B. zigongensis (Gao et al. 2004) and $Y$. chengjiangensis (Zhang 1985). B. youngi comes from the Early Jurassic Ziliujing Formation, well below the Xintiangou Formation that yields the pliosauroid specimens of Yunyang. As mentioned earlier, the tooth morphology is different between these pliosauroids. B. zigongensis from the Xiashaximiao Formation, above that of Yunyang pliosauroid while $Y$. chengjiangensis is from the same yellow-grey sandy mudstone of the Xintiangou Formation. As mentioned earlier, the morphological similarities of the vertebrae are often obscured by ontogenetic and intraspecific variations in Plesiosauria. With these in mind, it is difficult to evaluate these similarities taxonomically, especially when the relevant specimens are fragmentary. Whether or not the pliosauroid of Yunyang represents a new species or can be referred to a known species of the Sichuan Basin has to wait for the discovery of new and more complete materials. As compared with the pliosauroid specimens of Yunyang, however, it has to be noted that $Y$. chengjiangensis not only comes from the similar stratigraphical 
layer of the Xintiangou Formation but also its fossil locality is not too far (about $250 \mathrm{~km}$ ) from the site of the Yunyang pliosauroid sites. This indicates that the Yunyang pliosauroid specimens might be referable to $Y$. chengjiangensis. Again, to verify this needs to find new or more complete specimens. From the above discussion, the pliosauroid specimens from Yunyang can be only referred to Pliosauroidea in taxonomy as an indeterminate genus and species.

It has to be noted that with the Yunyang pliosauroid, there are at least five pliosauroids reported from the Jurassic in the Sichuan Basin, which separately come from the Daanzhai (Taanchai) Member (limestone) of the Lower Jurassic Ziliujing Formation (B. youngi), from the upper part of the lower Middle Jurassic Xintiangou Formation ( $Y$. chengjiangensis and the Yunyang pliosauroid), and from the upper Middle Jurassic Xiashaximiao Formation (B. zigongensis). All these named or unnamed pliosauroids are fragmentary, their taxonomic status (except for B. youngi) has not been revised, and their phylogenetic relationships have not been considered in any phylogenetic analysis. Under such a situation, it is too early to illustrate the origin and diversity of these pliosauroids in Sichuan Basin. However, it is clear that after the Triassic-Jurassic extinction, some basal members of the marine pistosauroids had to adapt to a freshwater environment in the Early Jurassic and survived at least to the end of the Middle Jurassic in Sichuan Basin.

\section{Conclusions}

We attribute the teeth, vertebrae and ribs specimens from Yunyang to Pliosauroidea based on the morphological features of teeth and cervical vertebrae. These specimens are too fragmentary to represent a new or a known species. Discovery of new and better-preserved specimens from the same formation is necessary to verify the Yunyang pliosauroid specimens in morphology and taxonomy.

The tooth crown morphology of the pliosauroids of Yunyang further supports the view that a high dental disparity occurred in pliosauroids before crossing the Jurassic-Cretaceous boundary. The present knowledge on the Chinese pliosauroids is too little to illustrate the origin or diversity of the plesiosaurians in the Sichuan Basin during the Jurassic, but it is certain that plesiosaurians survived to the end of the Middle Jurassic in the basin after adaptation to a freshwater environment during the Triassic-Jurassic transition.

\section{Acknowledgements}

We warmly thank Prof. Jun-Chang Lü (Institute of Geology) for his help in all aspects during the first stage of this project and his supervision of the preliminary draft of the manuscript. We are very grateful to Yu-Qing Zhang and Zu-Yan Chen for the specimen preparation, Rui-Hong Wang for taking photographs, and Shan Jiang and Bao-Qiao Hao (Zigong Dinosaur Museum) for providing comparative materials. We appreciate the efforts of Profs. Xiao-
Chun Wu (Canadian Museum of Nature) and Young-Nam Lee (Seoul National University) who carefully reviewed the manuscript, offering critical comments and suggestions that led to its great improvement.

\section{Authors' contributions}

XFW and FZ carried out the study, participated in the conceptualization and drafted the manuscript. HDY and CX carried out the fieldwork and geological data collection. ZYW participated in the fossil preparation and measurement. GZP conceived the project, participated in coordination and drafting the manuscript. The authors read and approved the final manuscript.

\section{Funding}

This study is supported by the National Nature Science Foundation of China (Grant no. 41672019 and 41688103), Dinosaur Fossil Protection and Research of Chongqing Planning and Natural Resources Bureau (Grant no. kj-2018035), Natural Science Foundation of Chongqing, China (Grant no. cstc2018jcyjAX0435) and Postdoctoral Project of Chongqing, China (Grant no. Xm2017069).

\section{Availability of data and materials}

The following information was supplied regarding data availability: The fossils were discovered by the field crew of Chongaing Laboratory of Geoheritage Protection and Research (CLGPR), No. 208 Hydrogeological and Engineering Geological Team, Chongqing Bureau of Geological and Mineral Resource Exploration and Development, Chongqing, and were prepared and deposited at CLGPR.

\section{Competing interests}

The authors declare that they have no competing interests.

\section{Author details}

${ }^{1}$ Chongqing Laboratory of Geoheritage Protection and Research, No. 208 Hydrogeological and Engineering Geological Team, Chongqing Bureau of Geological and Mineral Resource Exploration and Development, Chongqing 400700, China. ${ }^{2}$ Zigong Dinosaur Museum, Zigong 643000, Sichuan Province, China. ${ }^{3}$ Institute of Geology, Chinese Academy of Geological Sciences, Beijing 100037, China. ${ }^{4}$ China University of Geosciences (Beijing), Beijing 100083, China. ${ }^{5}$ Cores and Samples Centre of Natural Resources, Chinese Geological Survey, Beijing 100192, China.

Received: 13 December 2019 Accepted: 7 August 2020

Published online: 24 August 2020

\section{References}

Andrews, C.W. 1909. On some new Plesiosauria from the Oxford clay of Peterborough. Annals and Magazine of Natural History, London 8 (4): 418-429.

Andrews, C.W. 1922. Description of a new plesiosaur from the weald clay of Berwick (Sussex). Quarterly Journal of the Geological Society of London 78 (3): 285-298.

Bardet, N., and S. Hua. 1996. Simolestes nowackianus Huene, 1938 from the upper Jurassic of Ethiopia is a teleosaurid crocodile, not a pliosaur. Neues Jahrbuch für Geologie und Paläontologie - Monatshefte 2: 65-71.

Bartholomai, A. 1966. The discovery of plesiosaurian remains in freshwater sediments in Queensland. Australian Journal of Science 28: 437-438.

Benson, R.B.J., and S.P. Druckenmiller. 2014. Faunal turnover of marine tetrapods during the Jurassic-Cretaceous transition. Biological Reviews 89 (1): 1-23.

Benson, R.B.J., M. Evans, S.A. Smith, J. Sassoon, S. Moore-Faye, F.H. Ketchum, and R. Forrest. 2013a. A giant pliosaurid skull from the late Jurassic of England. PLoS One 8 (5): 1-34.

Benson, R.B.J., E.M.G. Fitzgerald, T.H. Rich, and P. Vickers-Rich. 2013b. Large freshwater plesiosaurian from the Cretaceous (Aptian) of Australia. Alcheringa 37 (4): 456-461.

Benson, R.B.J., H.F. Ketchum, D. Naish, and L.E. Turner. 2012. A new leptocleidid (Sauropterygia, Plesiosauria) from the Vectis formation (early Barremian-early Aptian; Early Cretaceous) of the Isle of Wight and the evolution of Leptocleididae, a controversial clade. Journal of Systematic Palaeontology 11: 233-250. 
Brown, D.S. 1981. The English upper Jurassic Plesiosauroidea (Reptilia) and a review of the phylogeny and classification of the Plesiosauria. Bulletin British Museum (Natural History), Geology 35 (4): 253-347.

Buffetaut, E., V. Suteethorn, H.Y. Tong, and R. Amiot. 2008. An Early Cretaceous spinosaurid theropod from southern China. Geological Magazine 145 (5): 745-748.

Cau, A., and F. Fanti. 2014. A pliosaurid plesiosaurian from the Rosso Ammonitico Veronese formation of Italy. Acta Palaeontologica Polonica 59 (3): 643-650.

Cruickshank, A.R.I. 1997. A Lower Cretaceous pliosauroid from South Africa. Annals of the South African Museum 105: 207-226.

Cruickshank, A.R.I., and R.E. Fordyce. 2002. A new marine reptile (Sauropterygia) from New Zealand: Further evidence for a Late Cretaceous austral radiation of cryptocleidid plesiosaurs. Palaeontology 45: $557-575$

de Blainville, M.H. 1835. Description de quelques espèces dereptiles de la Californie précédée de l'analyse d'un système général d' érpetolotgie et d'amphibiologie. Nouvelles Annales du Museum d'Histoire Naturelle de Paris 3: 233-272.

Dong, Z.M. 1980. A new Plesiosauria from the Lias of Sichuan Basin. Vertebrata PalAsiatica 18 (3): 191-199 (in Chinese).

Fischer, V., M.S. Arkhangelsky, I.M. Stenshin, G.N. Uspensky, and R.B.J. Benson. 2015. Peculiar macrophagous adaptations in a new Cretaceous pliosaurid. Royal Society Open Science 2 (150552): 1-12.

Gao, T., D.Q. Li, L.F. Li, and J.T. Yang. 2019. The first record of freshwater plesiosaurian from the middle Jurassic of Gansu, NW China, with its implications to the local palaeobiogeography. Journal of Palaeogeography 8 (1): 27. https://doi.org/10.1186/s42501-019-0043-5.

Gao, Y.H., Y. Ye, and S. Jiang. 2004. A new species of Bishanopliosaurus from middle Jurassic of Zigong, Sichuan. Vertebrata PalAsiatica 42 (2): 162165 (in Chinese).

Hampe, O. 2013. The forgotten remains of a leptocleidid plesiosaur (Sauropterygia: Plesiosauroidea) from the Early Cretaceous of Gronau (Münsterland, Westphalia, Germany). Paläontologische Zeitschrift 87 (4): 473-491.

Hornung, J.J., S. Sachs, and B.P. Kear. 2013. Sauropterygian fossils from the predominantly limnic-brackish Bückeberg Formation (Berriasian-early Valanginian, Early Cretaceous) of northwestern Germany - diversity, distribution, and palaeoecology. In Palaeobiology and Geobiology of Fossil Lagerstätten through Earth History. A joint conference of the "Paläontologische Gesellschaft" and the "Palaeontological Society of China". Abstracts Volume, ed. J. Reitner, Q. Yang, Y. Wang, and M. Reich, 75. Göttingen: Universität Göttingen.

Hou, L.H., X.K. Ye, and X.J. Zhao. 1975. Fossil reptiles from Fusui, Kwangshi. Vertebrata PlalAsiatica 13 (1): 24-36.

Huene, F.V. 1938. Ein Pliosauride aus Abessinien. Zentralblatt für Mineralogie Geologie und Palaeontologoie. Stuttgart (B) 1938: 370-376.

Kear, B.P. 2006. Plesiosaur remains from Cretaceous high-latitude nonmarine deposits in southeastern Australia. Journal of Vertebrate Paleontology 26 (1): 196-199.

Kear, B.P. 2007. A juvenile pliosauroid plesiosaur (Reptilia, Sauropterygia) from the Lower Cretaceous of South Australia. Journal of Paleontology 81: 154-162.

Kear, B.P. 2012. A review of Australia's Jurassic plesiosaurs. Palaeontology 55 (5): 1125-1138.

Kear, B.P., and P.M. Barrett. 2011. Reassessment of the Lower Cretaceous (Barremian) pliosauroid Leptocleidus superstes Anderews, 1922 and other plesiosaur remains from the nonmarine Wealden succession of southern England. Zoological Journal of the Linnean Society 161 (3): 663-691.

Ketchum, H.F., and R.B.J. Benson. 2010. Global interrelationships of Plesiosauria (Reptilia, Sauropterygia) and the pivotal role of taxon sampling in determining the outcome of phylogenetic analyses. Biological Reviews 8 (2): 361-392.

Li, C.H. 2016. Study on the Jurassic Lithofacies and Paleogeography of Sichuan Basin [Master's thesis]. Chengdu: Chengdu Univerisity of Technology (in Chinese with English abstract).
Li, N., H. Dai, C. Tan, X.F. Hu, Z.Y. Wei, Y. Lin, G.B. Wei, D.L. Li, L. Meng, B.Q. Hao, H.L. You, and G.Z. Peng. 2019. A neornithischian dinosaur from the middle Jurassic Xintiangou formation of Yunyang, Chongqing: The earliest record in Asia. Historical Biology. https://doi.org/10.1080/ 08912963.2019.1679129

Madzia, D. 2016. A reappraisal of Polyptychodon (Plesiosauria) from the Cretaceous of England. PeerJ 4 (1): e1998. https://doi.org/10.7717/peerj. 1998

Madzia, D., and M. Machalski. 2017. Isolated pliosaurid teeth from the Albian-Cenomanian (Cretaceous) of Annopol, Poland. Acta Geologica Polonica 67 (3): 393-403.

O'Keefe, F.R. 2001. A cladistic analysis and taxonomic revision of the Plesiosauria (Reptilia: Sauropterygia). Acta Zoologica Fennica 213: 1-63.

O'Keefe, F.R. 2002. The evolution of plesiosaur and pliosaur morphotypes in the Plesiosauria (Reptilia: Sauropterygia). Palaeobiology 28 (1): 101-112.

O'Keefe, F.R., and N. Hiller. 2006. Morphologic and ontogenetic patterns in elasmosaur neck length, with comments on the taxomic utility of neck length variables. Paludicola 5 (4): 206-229.

Owen, R. 1860. On the order $s$ of fossil and recent Reptilia and their distributions in time. Report of the British Association for the Advancement of Science 29: 153-166.

Peng, G.Z., Y. Ye, Y.H. Gao, C.K. Shu, and S. Jiang. 2005. Jurassic Dinosaur Faunas in Zigong, 45-48. Chengdu: People's Publishing House of Sichuan (in Chinese).

Sachs, S., J.J. Hornung, and B.P. Kear. 2016. Reappraisal of Europe's most complete Early Cretaceous plesiosaurian: Brancasaurus brancai Wegner, 1914 from the "Wealden facies" of Germany. Peer J 4: e2813. https://doi. org/10.7717/peerj.2813.

Sachs, S., J.J. Hornung, J.N. Lallensack, and B.P. Kear. 2017. First evidence of a large predatory plesiosaurian from the Lower Cretaceous non-marine 'Wealden facies' deposits of northwestern Germany. Alcheringa an Australasian Journal of Palaeontology 642: 1-8.

Sassoon, J., D. Foffa, and R. Marek. 2015. Dental ontogeny and replacement in Pliosauridae. Royal Society Open Science 2: 150384. https://doi.org/10. 1098/rsos.150384.

Sato, T. 1998. Description of a Plesiosaurian Fossil (Reptilia: Sauropterygia) from Hokkaido, Japan, and a Review of Plesiosaurs from Asia [Master's thesis]. Ohio: University of Cincinnati.

Sato, T., D.A. Eberth, E.L. Nicholls, and M. Manabe. 2005. Plesiosaurian remains from non-marine to paralic sediments. In Dinosaur Provincial Park, ed. P.J. Currie and E.B. Koppelhus, 249-276. Bloomington and Indianapolis: Indiana University Press, America.

Sato, T., T. Hanai, S. Hayashi, and T. Nishinura. 2018. A Turonian polycotylid plesiosaur (Reptilia: Sauropterygia) from Obira town, Hokkaido, and its biostratigraphic and paleoecological significance. Paleontological Research 22 (3): 265-278.

Sato, T., Y. Hasegawa, and M. Manabe. 2006. A new Elasmosaurid plesiosaur from the Upper Cretaceous of Fukushima, Japan: Palaeontology (Oxford) 49 (3): 467-484.

Sato, T., C. Li, and X.C. Wu. 2003. Restudy of Bishanopliosaurus youngi Dong 1980, a freshwater plesiosaurian from the Jurassic of Chongqing. Vertebrata PalAsiatica 41 (1): 17-33.

Sato, T., and X.C. Wu. 2006. Review of plesiosaurians (Reptilia: Sauropterygia) from the Upper Cretaceous horseshoe canyon formation in Alberta, Canada: Paludicola 5: 150-169.

Sauvage, H.E. 1873. Notes sur les reptiles fossils. Bulletin de la Société. géologique de. France, Paris 3 (1): 365-380.

Seeley, H.G. 1869. Index to the fossil remains of Aves, Ornithosaurier and Reptilia in the Woodwardian Museum of the University of Cambridge, xxiii-143. Cambridge.

Storrs, G.W. 1991. Anatomy and relationships of Corosaurus alcovensis (Reptilia: Sauropterygia) and the Triassic Alcova limestone of Wyoming. Bulletin of the Peabody Museum of Natural History 44: 1-151.

Sues, H.D. 1987. Postcranial skeleton of Pistosaurus and interrelationships of the Sauropterygia (Diapsida). Zoological Journal of the Linnean Society 90: 109-131. 
Tan, C., H. Dai, J.J. He, F. Zhang, X.F. Hu, H.D. Yu, N. Li, G.B. Wei, G.Z. Peng, Y. Ye, Q.N. Zhang, X.X. Ren, and H.L. You. 2019. Discovery of Omeisaurus (Dinosauria: Sauropoda) in the middle Jurassic Shaximiao formation of Yunyang, Chongqing, China. Vertebrata PalAsiatica 57 (2): 105-116.

Tarlo, L.B. 1960. A review of the upper Jurassic pliosaurs. Bulletin British museum (natural history). Geology 4 (5): 145-189.

Thulborn, R.A., and A. Warren. 1980. Early Jurassic plesiosaurs from Australia. Nature 285 (5762): 224-225.

Tschanz, K. 1989. Lariosaurus buzzii n. sp. from the middle Triassic of Monte san Giorgio (Switzerland) with comments on the classification of nothosaurs. Palaeontographica A 208: 153-179.

Vajda, V., and J.I. Raine. 2010. A palynological investigation of plesiosaurbearing rocks from the Upper Cretaceous Tahora formation, Mangahouanga, New Zealand. Alcheringa 34: 359-374.

Vandermark, D., A.J. Tarduno, and B.D. Brinkman. 2006. Late Cretaceous plesiosaur teeth from Axel Heiberg Island, Nunavut, Canada. Arctic 59 (1): 79-82.

Vavrek, M.J., B.C. Wilhelm, E.E. Maxwell, and H.C. Larsson. 2014. Arctic plesiosaurs from the Lower Cretaceous of Melville Island, Nunavut, Canada. Cretaceous Research 50: 273-281.

Wang, Q.W. 2008. Reconstruction of paleoenvironment of Mesozoic dinosaurian fauna in Sichuan Basin, 1-197. Beijing: Geological Publishing House (in Chinese).

Wang, Q.W., Z.W. Kan, X.H. Liu, B. Liang, and B. Zhu. 2008. The Mesozoic sporopollen assemblage in the Sichun Basin and its significance to paleovegetation and paleochimate. Sichuan Geologica Sinica 28 (2): 8995 (in Chinese).

Wang, Y.D., B.H. Fu, X.P. Xie, Q.S. Huang, K. Li, G. Li, Z.S. Liu, J.X. Yu, Y.H. Pan, N. Tian, and Z.K. Jiang. 2010. Continental Triassic and Jurassic of Sichuan Basin, 23-114. Hefei: University of Science and Technology of China Press both in Chinese and English.

Welles, S.P. 1943. Elasmosaurid plesiosaurs with description of new material from California and Colorado. Memoir of the University of California, Berkeley 13: 125-254

Wiffen, J., V. De Buffre'nil, A. De Ricale's, and J.M. Mazin. 1995. Ontogenetic evolution of bone structure in Late Cretaceous Plesiosauria from New Zealand. Geobios 28: 625-640.

Wu, S.Z. 1987. The discovery of Pliosauria and its significance in South Xinjiang. Xinjiang Geology 5 (1): 105-107 (in Chinese).

Xiao, Y.W., K.H. Chen, and D.B. Cao. 1991. First discovery of Sinopliosaurus fossil from the upper Triassic in central Yunan. Regional Geology of China 2: 180-182 (in Chinese).

Ye, Y., G.Z. Peng, and S. Jiang. 2012. A review of dinosaur footprints in Sichuan Basin. Journal of Geology 36 (2): 129-133 (in Chinese with English abstract).

Young, C.C. 1941. New founds on Sichuan Mesozic reptiles. Geological Review 6 (Z1): 215-220 (in Chinese).

Young, C.C. 1942. Fossil vertebrates from Kuangyuan, N. Szechuan, China. Bulletin of the Geological Society of China 22 (2): 293-309.

Young, C.C. 1944. On the reptilian remains from Weiyuan, Szechuan, China. Bulletin of the Geological Society of China 24 (3): 187-209.

Young, C.C. 1973. Plesiosaur remains discovered in Dsungar Basin, Sinkiang. Memoirs of the Institute of Vertebrate Paleontology and Paleoanthropology 11: 13-17.

Zhang, Y.H. 1985. A new plesiosaur from middle Jurassic of Shuan Basin. PlalAsiatica 23 (3): 235-242 (in Chinese).

Zverkov, N.G., V. Fischer, D. Madzia, and R.J. Benson. 2018. Increased pliosaurid dental disparity across the Jurassic-Cretaceous transition. Palaeontology 61 (6): 825-846.

\section{Publisher's Note}

Springer Nature remains neutral with regard to jurisdictional claims in published maps and institutional affiliations.

\section{Submit your manuscript to a SpringerOpen ${ }^{\circ}$ journal and benefit from:}

- Convenient online submission

- Rigorous peer review

- Open access: articles freely available online

- High visibility within the field

- Retaining the copyright to your article

Submit your next manuscript at $\boldsymbol{\nabla}$ springeropen.com 